\title{
THE EMERGENCE AND IMPLEMENTATION OF HEALTH GOALS
}

\author{
PETER M. GOLLWITZER ${ }^{1, *}$ and GABRIELE OETTINGEN ${ }^{2, * *}$ \\ 'Universität Konstanz, Postfach 5560 D39, D-78434 Konstanz, Germany; \\ ${ }^{2}$ Max Planck Institute for Human Development and Education, Lentzeallee 94, \\ D-14195 Berlin, Germany
}

\begin{abstract}
Modern theorizing on goals is applied to an analysis of the implementation and the emergence of health goals. First, a model of action phases and its concomitant concepts of implemental mindsets and implementation intentions (Gollwitzer, 1990; 1993) are used to explore how the initiation of health goal directed behaviors can be facilitated and how the performance of health goal directed actions is enhanced. Second, recent theorizing on the psychology of thinking about the future (Oettingen, 1996; 1997) is employed to discuss conditions and processes of the emergence of health goals. It is suggested that contrasting positive fantasies about the future with reflections on the negative aspects of reality create binding health goals that reliably affect people's behaviors.
\end{abstract}

KEY WORDS: Action phases, fantasies about the future, fantasy-reality contrast, implementation intentions, mindsets.

Health goals focus on the promotion of health and the prevention of illness. Accordingly, they specify desired health outcomes, such as a healthy blood pressure and weight, and are concerned with the respective health enhancing and disease preventing behaviors. The most prominent health-enhancing and disease preventing behaviors (see Taylor, 1991) are exercising, dieting, accident prevention as well as preventative self-examination (e.g., of breasts or testicals). Health goals may not only specify health enhancing and disease preventing behaviors, they may also be targeted at discouraging health compromising behaviors, such as alcohol and drug abuse, smoking, "Type A" behavior, risky diets as well as dangerous sports.

For people who suffer from an acute or chronic illness or are plagued by a disability (Johnston, 1996), health goals may also focus on the management of these hardships. These behaviors may range from the efficient use of health services, improving patient-practitioner interactions, coping with pain, complying with medical regimens, effective rehabilitation exercises, and specific management of disabilities.

The current literature on the self-regulatory determinants of health behaviors primarily focuses on motivational variables. The health belief model (Hochbaum, 1958; Rosenstock, 1966; 1974) lists general health values, specific beliefs about vulnerability to a particular disorder, and beliefs about the consequences of this disorder. For example, a person may consider changing her diet to include low cholesterol foods, if she values health, feels personally threatened by the possibility of heart disease and believes that the threat of heart disease is severe. Whether or not a health threat leads to the actual implementation of the respective health behaviors, however, further depends on whether

* E-mail: Gollwitz@soz.psychologie.uni-konstanz.de.

** E-mail: Oettingen@mpib-berlin.mpg.de. 
a person believes that these behaviors will reduce the experienced threat. This in turn is determined by both the belief that the specific measure can be effective and the belief that the benefits of the health behavior exceed its costs.

The theory of reasoned action (Fishbein, 1980) also specifies the motivational determinants of values and expectancies. Attitudes towards health behaviors are based on beliefs about the likely outcomes of these behaviors (outcome expectations) and the evaluations of these outcomes (outcome values). In addition, subjective norms are said to play a role. They derive from what other people think one should do (expectation) and the motivation to comply with these normative references (value). In a recent extension of this theory by Ajzen, called the theory of planned behavior, a further motivational determinant is added: perceived behavioral control over the respective behavior (Ajzen, 1985). Bandura (1977; 1986), in his social-cognitive theory of behavior, has referred to this latter variable as self-efficacy beliefs. An important aspect of the Ajzen and Fishbein models is the proposal that the listed determinants affect behavior by the mediation of a behavioral intention. The behavioral intention construct captures the individual's commitment or goal to perform the specified behavior. The strength of this goal (or behavioral intention) is said to be dependent on the strengths of the motivational variables listed, and the translation of the intention into behavior is the more effective, the stronger the intention.

At first glance it appears that Ajzen and Fishbein have transcended the assumption that behavior is solely dependent on motivational variables (expectations and values) by introducing the concept of behavioral intention (or goal). However, a closer look reveals that the effective translation of intention into behavior is a function of the strength of the behavioral intention, which is still solely determined by motivational variables. This implies that the individual cannot perform over and above the strength of her intention, which means that volitional strategies play no role over and above the individual's motivation. This conceptualisation is unfortunate, when predicting health behaviors. Usually such behaviors are not highly motivated to begin with (e.g., reducing alcohol consumption or switching from a high fat to a low fat diet), as the respective beliefs are seldom strongly held and the respective values or perceived incentives are mostly low. Moreover, during the attempt to implement health goals the individual is confronted with compromising distractions and temptations (e.g., professional obligations for a person with the goal to exercise regularly or social drinking for a person who has set the goal to abstain from alcohol) and often gets in conflict with bad health habits (e.g., a high calorie diet).

In summary, a self-regulatory view of the control of health behaviors needs to spell out the strategies that go beyond the strength of a person's intention (or goal commitment) and thus motivation. These strategies may relate to how the goal is framed or to volitional skills necessary for effectively translating a given intention into goal-directed behavior.

\section{MODERN GOAL THEORIES AND THE CONTROL OF GOAL ATTAINMENT}

Modern goal theories assume that whether or not people meet their goals depends on both how goal content is framed and how people regulate goal-directed activities (Gollwitzer and Moskowitz, 1996). Content theories of goal pursuit focus on the thematic properties of the set goal and how these affect the regulation of goal pursuit and actual goal attainment. Such theories attempt to explain differences in goal-directed behaviors in terms of what is specified as the goal by the individual, because the content characteristics of the goal are expected to affect a person's goal pursuit. Goal content has been considered both 
in terms of the different needs on which it is based (e.g., autonomy versus materialistic needs, Deci and Ryan, 1991; Kasser and Ryan, 1993) as well as in terms of implicit theories (e.g., entity theories versus incremental theories of ability or morality, Dweck, $1991 ; 1996)$. Numerous other aspects of goal content have been suggested, such as specific/abstract (Emmons, 1992; Locke and Latham, 1990), proximal/distal (Bandura and Schunk, 1981), and positive versus negative outcome focus (Higgins, Roney, Crowe and Hymes, 1994).

Self-regulation theories of goal striving, however, focus on the question of how people overcome certain implementation problems. Setting a goal is just a first step towards goal attainment which is followed by a host of implementation problems that need to be solved successfully. These problems are manifold as they pertain to initiating goal-directed actions and bringing them to a successful ending. Various theoretical approaches have delineated useful self-regulatory strategies, and addressed questions of why and how these strategies are effective. Typical self-regulatory problems of goal pursuit are, for example, warding off distractions (see implemental mindsets, Gollwitzer, 1990; various action control strategies, Kuhl, 1984; Kuhl and Beckmann, 1994), flexibly stepping up efforts in the face of difficulties (see effort mobilization, Wright and Brehm, 1989), compensating for failures and shortcomings (see self-regulation of motivation, Bandura, 1991; discrepancy reduction, Carver and Scheier, 1981; symbolic self-completion, Wicklund and Gollwitzer, 1982), and negotiating conflicts between goals (see intelligent pursuit of life tasks, Cantor and Fleeson, 1994; conflict resolution in the face of contradictory personal strivings, Emmons and King, 1988).

All these theoretical approaches to the analysis of goal pursuit can, in our view, be profitably applied to the pursuit of health goals. People should benefit more from setting themselves health goals based on autonomy needs (e.g., losing weight for the purpose of self-actualization; Kasser and Ryan, 1993) as compared to materialistic needs (e.g., losing weight to be attractive to high status people). Goals based on incremental theories of health (i.e., health can be maintained and enhanced by effort and learning; Dweck, 1996) should be more profitable than goals based on entity theories (i.e., health is conceived of as a fixed capacity which people have a certain amount of). In addition, health goals that are framed specifically (e.g., exercising 20 minutes a day; Locke and Latham, 1990), proximally (e.g., exercising during the upcoming weekend; Bandura and Schunk, 1981), and with a positive outcome focus (e.g., deciding to exercise; Higgins et al., 1994) should lead to better health performances than goals that are framed abstractly (e.g., exercising a lot), distally (e.g., exercising during the upcoming summer), and with a negative outcome focus (e.g., deciding not to be lazy). Similarly, self-regulation theories of goal pursuit inform us how people who have set themselves health goals can maximize the translation of these goals into behavior. In the next section of this paper we will present a particular self-regulation theory of goal-pursuit, the model of action phases (Heckhausen, 1991, Chap. 6; Gollwitzer, 1990; 1993), and explore whether and how the self-regulatory strategies discovered within this theoretical framework (mindsets and implementation intentions) are relevant to the regulation of people's health goals.

\section{The Model of Action Phases.}

The model is based on the conceptual distinction between the motivational issue of goal setting and the volitional (willful) issue of goal striving (Lewin, Dembo, Festinger and Sears, 1944). It is assumed that the principles guiding goal selection and those guiding 
goal achievement are qualitatively different (Kuhl, 1984). The model provides a temporal perspective that starts with the awakening of people's wishes prior to goal setting and extends to the evaluative thoughts people have once goal striving has led to some kind of outcome. The sequence of events within this comprehensive time frame is spelled out in terms of four successive, concrete tasks that need to be accomplished in order to promote wish fulfillment. The first of these tasks consists of deliberating wishes and setting preferences in the predecisional phase. People cannot act on all of their wishes at once some wishes may contradict each other, others are too difficult to implement - and life is simply too short to follow all of one's wishes. As a consequence, people have to decide which of the many wishes they prefer to pursue and preferences are established by employing the evaluative criteria of feasibility and desirability. A wish's feasibility (e.g., to keep an athletic body) is determined by reflecting on the chances that it can be realized (e.g., "Do I possess the necessary skills and talent, time and equipment, access to relevant opportunities?"). Desirability relates to the expected value of wish fulfilment (i.e., the likelihood of the positive and negative consequences of having achieved the desired wish, such as an anticipated positive or negative self-evaluation, evaluation by others, progress towards some important life goal, excitement of acting on the wish, and external costs or rewards). The perceived feasibility and desirability of a wish are not fixed and depend on whether the wish is scrutinized in the context of other complimentary (e.g., getting to know people) or contradictary (e.g., spending more time on one's work) wishes.

The model suggests, however, that progress towards fulfilling a wish will not occur simply through judging a wish high in feasibility and desirability. Rather, progress demands a decision to act on a given wish. The model speaks of a transition from wishes and desires to binding goals, the latter being accompanied by a feeling of determination or obligation to fulfill the implied wish. Forming a goal commitment, however, is just a prerequisite for making progress towards wish fulfilment. Once a decision has been made the next task to be solved is promoting the initiation of goal-directed actions. This may be quite simple when the necessary goal-directed actions are well practiced or routine. However, difficulties may arise when people are still undecided about where and how to act (e.g., when a person has set herself the goal to exercise). In such cases the execution of goal-directed actions has to be prepared. The model of action phases speaks of this period prior to the initiation of goal-directed action as the preactional phase. To advance further on the way from wishes to action, individuals should reflect and decide on when, where, and how to act, thus creating plans for action.

With the initiation of goal-directed behaviors individuals enter the actional phase that comprises the task of bringing goal-directed behaviors to a successful conclusion. To serve this purpose effectively, the individual should flexibly respond to situational opportunities and demands, and when hindrances are encountered, she should readily increase her efforts. The final action phase, called postactional, is characterized by the task of evaluating goal achievement by comparing what has been achieved to what was desired; in this stage the individual assesses whether the desired outcomes have been attained or whether it is necessary to continue striving.

In summary, the model of action phases attempts to delineate distinct tasks within the course of wish fulfilment. In temporal order these tasks are as follows: setting preferences between or among wishes, making plans for goal-directed actions, bringing initiated actions to a successful ending, and evaluating action outcomes. The model's primary objective is to identify potential problems people may encounter when attempting to translate wishes and desires into reality. By doing so, the model has stimulated further 
concepts that more directly touch self-regulatory processes helping people to overcome these problems. These are the concepts of mindsets and implementation intentions.

\section{The Concept of Mindsets}

This concept was suggested by the Würzburg school of thought (Külpe, 1904; Watt, 1905). It was used to explain the experimental observation that instructing participants to solve a specific task creates a related cognitive set that furthers the solution of the task at hand. Apparently, when a person becomes involved with a given task, relevant cognitive procedures are activated and hence become more easily accessible. When this idea is applied to the model of action phases, it follows that different mindsets (i.e., general cognitive orientations with distinct features) should emerge when people become involved with the different tasks associated with the various action phases, and these mindsets should be endowed with cognitive features that facilitate the respective task at hand.

In various studies (for a summary, see Gollwitzer, 1990) it has been demonstrated that participants who had been asked to deliberate a personal wish developed a different cognitive orientation (i.e., a deliberative mindset) than participants who had been induced to plan the implementation of a personal goal (i.e., an implemental mindset). Comparing the features of the deliberative with the implemental mindsets, it became apparent that the different cognitive orientations were functional for solving the respective tasks, that is, setting preferences between wishes and initiating goal-directed actions. From a self-regulation point of view these findings imply that people can acquire these beneficial mindsets by getting involved with intensive deliberation or intensive planning.

\section{The Concept of Implementation Intentions}

In the preactional phase people face the task of initiating goal-directed actions. As long as the implementation of a chosen goal does not follow habitualized routes, an individual has to make further decisions. This time the choice is not among wishes, but among competing ways of realizing a chosen wish (i.e., a goal). Such a decision takes the format of "I intend to do $\mathrm{x}$, when situation $\mathrm{y}$ is encountered" and its result can be referred to as an implementation intention (Gollwitzer, 1993). In an implementation intention, an anticipated future situational cue (opportunity) is linked to a certain goal-directed behavior. Holding implementation intentions commits the individual to performing certain goal-directed behaviors when the critical situation is actually encountered.

Implementation intentions should not be confused with goal intentions. Goal intentions are a result of a decision among competing wishes and desires. Such decisions take the format of "I intend to achieve $x$ ", whereby the $x$ specifies a desired end-state, such as the execution of a concrete behavior or the attainment of a desired outcome. Accordingly, the consequence of having formed a goal intention is a feeling of commitment to achieve this end-state. Hierarchically, goal intentions are superior to implementation intentions; the latter are formed in the service of the former.

From a self-regulatory point of view, the formation of implementation intentions promotes the initiation of goal-directed action by specifying anticipated situational cues and linking them to specific to-be-performed goal-directed behaviors. Gollwitzer (1993) assumes that implementation intentions delegate the control of this behavior to the critical situational cues. As a consequence, these situational cues are more easily detected, more readily attended to, and more efficiently recalled. In the presence of these cues, the specified 
behavior becomes elicited automatically. Action initiation is immediate, demands little cognitive capacity, and is started even when the critical situation has not been consciously processed. Furnishing goal intentions with implementation intentions, therefore, transforms the self-regulation of goal pursuit from conscious and effortful regulation into direct control through environmental cues.

\section{PROBLEMS OF GOAL IMPLEMENTATION}

Problems of goal implementation can be classified into two categories. The first set of problems involves getting started (remember the task of the preactional phase in the action phase model). For a number of reasons (to be spelled out below), people miss good opportunities to act and thus delay goal achievement. The second set of problems involves ensuring that, once started, goal pursuits are successfully completed. People often give up in the face of difficulties, fail to ward off distractions, and have trouble resuming goal pursuit once disruptions have occurred. How can implementation intentions and implemental mindsets alleviate such problems?

\section{Getting Started: Facilitative Effects of Implementation Intentions}

Goals that are furnished with implementation intentions should show a comparatively higher completion rate. As Lewin and his collaboraters observed (Lewin, 1926; Mahler, 1933; Ovsiankina, 1928), once a goal-directed action has been started, chances for its eventual completion are substantially raised. Accordingly, we ran two studies exploring whether or not implementation intentions raise the completion rate of longer-term projects (Gollwitzer and Brandstätter, Studies 1 and 2; 1997). In the first study, we asked college students prior to Christmas break to each name two projects they intended to achieve during their vacation, one difficult to implement and the other easy to implement. For both types of projects participants indicated such goals as writing a seminar paper, settling an ongoing family conflict, or engaging in sports activities. When we asked participants whether they had formed intentions on where and when to get started (i.e., implementation intentions), about two thirds - again for both types of goals - responded positively.

After Christmas vacation we contacted the participants and checked on project completion. For the projects that were difficult to implement, two out of three of the participants who had formed implementation intentions had carried it out. Participants without implementation intentions, however, mostly failed to complete their projects (only one quarter were successful). For the projects that were easy to implement, completion rate was very high (four out of five), regardless of whether or not participants had formed implementation intentions. Participants had also been asked to indicate how they perceived certain qualities of the named projects (e.g., importance of project completion, likelihood of potential obstacles, perceived closeness to project completion). On the basis of this data it could be confidently ruled out that the assessment of implementation intentions was a surrogate for goal quality variables which might have produced the observed pattern of completion rates.

The findings of the above study were corroborated in an analogous experiment in which the experimenters set participants a goal that was difficult to implement (Gollwitzer and Brandstätter, 1997, Study 2). In this experiment all participants were asked, again prior to Christmas break, to complete the same type of project. More specifically, participants 
were requested to write a report on how they spent Christmas Eve. This report was to be written no later than 48 hours after the event and then sent to the experimenters who were supposedly conducting a demographic study on how people spend their holidays in modern times.

Half of the participants were randomly chosen and then instructed to form implementation intentions. They were handed a questionnaire that requested them to specify when and where they intended to write the report during the critical 48 hours. The other half of the participants were not requested to pick a specific time and place for implementing this project. When participants' reports arrived in the mail after Christmas, they were analysed in terms of the dates when they were written. It turned out that three-quarters of the implementation intention participants wrote the report in the requested time period, whereas only one-third of the control participants managed to do so. It would be tempting to explain this finding in terms of obedience to the authority of the experimenter - the experimenters, being aware of this problem, however, granted participants absolute anonymity.

Given that most health promoting and disease preventing projects are subjectively perceived as difficult or unpleasant to implement (e.g., starting to regularly exercise for a fifty year old person; changing one's unhealthy diet, to which one has adhered to for one entire life; engaging in difficult rehabilitation activities after a stroke; walking for patients with arthritis, etc.), implementation intentions should have a substantial impact on translating health goals into action. Indeed, women who had set themselves the goal of performing breast self-examination during the next month (BSE; Orbell, Hodgkins and Sheeran, 1997) greatly benefited from forming implementation intentions. Participants were university students or administrative staff who were first asked to indicate how strongly they intended to perform BSE during the next month. To create relevant implementation intentions, participants were asked to write down where they would perform $\mathrm{BSE}$ in the next month and at what time of the day. Of the participants who had reported strong intentions to perform BSE during the next month, $100 \%$ did so when they had been induced to form additional implementation intentions. If no additional implementation intentions were formed, however, the strong goal intention alone only produced $53 \%$ of goal completion.

How do implementation intentions facilitate action initiation? Problems of the initiation of goal-directed action pertain to the following issues: when people are highly absorbed in an ongoing activity, wrapped up in demanding ruminations, gripped by an intense emotional experience, or simply tired, chances are high that they do not seize an available opportunity to act on their goals, simply because the opportunity fails to attract attention (e.g., a restaurant that offers low cholesterol food for the person with the health goal of reducing her cholesterol level). The reason for this is that attention is focused on other things that have nothing to do with the question of how to achieve the intended goal. But even when people search for appropriate opportunities in a given situational context, they may not detect it simply because it is not obvious at first sight (e.g., when in a club offering social activities people fail to recognize the available sports opportunities). Finally, the initiation of goal-directed action often becomes a problem, because people let those opportunities slip that present themselves only for a short moment (e.g., when a migrane patient fails to take his medication at the onset of symptoms). What is needed here is an immediate initiation of appropriate goal-directed behavior.

Gollwitzer (1993) theorized that implementation intentions which specify anticipated situational cues and link them to concrete goal-directed behaviors are ideally suited to 
alleviate these problems. By forming implementation intentions the mental representation of the anticipated situational cue becomes highly activated and thus easily accessible. This has attentional, perceptual, and behavioral consequences that should alleviate the problems listed.

First, regarding the attentional consequences, it was observed in a dichotic-listening task (Bargh, 1982; Johnston and Dark, 1986) that critical words describing the anticipated situational cues were highly disruptive to focused attention. Participants' performance of shadowing (i.e., efficient repeating of the words presented to the attended channel) was severely hampered when critical words were presented to the non-attended channel. Apparently, even when efforts are made to direct attention to the shadowing task, the critical words still managed to attract attention as indicated by the weakened shadowing performance. In dichotic listening research the critical situational cues are presented to participants in terms of verbal descriptions only. In real life, when a person enters a situational context that entails such critical cues not just as words, their potential to attract attention and thus to disrupt focused attention should be even stronger. This implies that opportunities to act as specified in implementation intentions will not easily escape people's attention even when people focus on other things (e.g., worries, strong emotions, the conscious pursuit of competing goals) besides the respective goal pursuit.

Second, to assess the perceptual processes of implementation intentions, an experiment by Steller (1992) employed the embedded figures test (Gottschaldt, 1926; Witkin, 1950). This test consists of complex geometrical figures (b-figures) that contain a smaller partial figure (a-figure). The a-figure is hidden within the b-figures according to Gestalt principles and is thus difficult to detect. Still, following the idea that implementation intentions would lead to heightened accessibility and thus better detection of the a-figure, it was observed that participants showed an enhanced detection performance when they had formed implementation intentions that used the a-figure as the critical situational cue.

Third, the postulated behavioral readiness as a result of forming implementation intentions was demonstrated in a series of three experiments. In the first experiment (Gollwitzer and Brandstätter, 1997, Study 3) participants were induced to form implementation intentions that specified good opportunities to present counterarguments to a series of racist remarks made by a confederate. When participants were finally allowed to counterargue, implementation intention participants initiated their counterarguments more immediately when these good opportunities arose than mere goal intention participants. In a second experiment (Brandstätter, 1992, Study 2) which involved a button pressing task embedded as the secondary task in a dual task paradigm, participants were induced to form the goal intention to press a button as fast as possible whenever numbers appeared on the screen but not when letters were shown. Participants in the implementation intention condition were asked to form the further intention to press the button particularly fast when the number 3 was presented. Implementation intention participants showed a substantial increase in speed (the number 3 led to faster reactions than the other numbers) as compared to a control group and this effect was independent of whether the simultaneously demanded primary task was easy or difficult to perform. Apparently, the immediacy of responding as induced by implementation intentions is effortless in the sense that it does not put much cognitive load on limited processing resources, and thus persists even when the cognitive demands of the primary task in a pair of tasks are high. In a third experiment (Malzacher, 1992) it was observed that the goal-directed behavior specified in an implementation intention is triggered without any conscious intent once the critical situational context is encountered. Participants in a study employing a retaliation. 
paradigm modeled on Zillman and Cantor (1976), formed the goal intention to respond to an insult by the experimenter in the form of a complaint spoken directly to the transgressor. Some participants also formed implementation intentions of the following form: "As soon as I see the experimenter again, I will tell her what an unfriendly person she is". In a subsequent, supposedly independent cognitive experiment, participants were asked to read a series of successively presented adjectives as quickly as possible from a screen. The adjectives were either positive or negative words, suitable for describing people. Shortly before (about $100 \mathrm{msec}$ ) each adjective, either a neutral face or the face of the unfriendly experimenter were subliminally presented (presentation time was less than $10 \mathrm{msec}$ ). Negative adjectives presented directly after the face of the unfriendly experimenter tended to be read faster than those presented directly after the neutral face, and positive adjectives were read much more slowly after the unfriendly experimenter's face than after the neutral face. This data pattern was only observed for implementation intention participants and failed to show up for mere goal intention participants. Apparently, the situational cues specified in an implementation intention directly elicit cognitive processes without conscious intent, in this case the activation of relevant knowledge and the inhibition of irrelevant knowledge, which facilitates the initiation of the intended action. The mere formation of a goal intention is not sufficient to produce this effect.

In summary, it appears that implementation intentions lead to the heightened activation of the mental representation of the specified situational cues. As a consequence, these cues are more easily detected and more readily attended to. In addition, the reported findings on the behavioral readiness induced by implementation intentions suggests that the commitment which people attach to the behavior-situation contingency that is proclaimed in their implementation intention creates strong links which normally can only be attained through frequent and consistent situation-response pairings. As this latter procedure leads to the automatic, direct environmental control of behavior (Bargh, 1992; 1994), one could argue that implementation intentions also achieve this effect. In other words, implementation intentions may be conscious mental acts that set up contingencies which will then lead to the automatic, environmental control of behavior.

From the perspective of health psychology, these effects of implementation intentions are important, as the crucial objective of any intervention in health behavior is to first initiate behavioral control by helping the patient to set positive health goals and then to transform this conscious behavioral control to automatic and thus habitual behavioral control. This habitualization of goal-directed behavior may be particularly difficult in the case of health behaviors, because such behaviors are mostly unpleasant and thus do not suggest themselves for frequent and consistent execution. But habitual action initiation can also be achieved by the simple mental act of forming implementation intentions. In the study on performing BSE (Orbell et al., 1997), this became evident by the following observations. Whereas old habits were the best predictors of performing BSE in the next month for participants who had not formed implementation intentions, the predictive power of old habits was nil as soon as participants had formed implementation intentions. Apparently, implementation intentions had created "new habits." This interpretation is supported by the finding that all of the implementation intention participants performed BSE exactly in that situation and at the time they had specified.

Are the effects of implementation intentions independent of the respective goal intentions? As the Orbell et al. study and the findings reported above (for details, see Gollwitzer, 1993) demonstrate, implementation intentions formed in the service of goal 
intentions have a substantial effect on effective goal pursuit over and above the mere goal intentions. If one follows Ajzen's and Fishbein's theorizing, the strength of the goal intention represents a person's motivation to reach the goal. Consequently, the effects of mere motivation on action can be enhanced by implementation intentions.

However, the question remains whether implementation intentions are still effective when the goal intentions on which they are based are weak or have been either completed or abandoned. From a functional point of view, this should not be the case. As soon as no relevant goal exists, implementation intentions should not evince their typical effects. An experiment by Seehausen, Bayer and Gollwitzer (1994) supports this view. When participants were told that the goal intention would no longer have to be implemented, the typical effects of implementation intentions (in this case the postulated heightened accessibility of the situational cues was measured by a recall test) did not vanish immediately, but were completely gone after 48 hours. In addition, it was observed that varying the strength of participants' commitments to their implementation intentions had an effect. When participants were told that they were the kind of people who would benefit from rigidly adhering to their plans versus the kind of person who would benefit from staying flexible, the former participants showed strong implementation intention effects whereas the latter failed to do so.

In summary, feeling strongly about achieving the goal intention appears to be a prerequisite for the effects of implementation intentions. On the basis of such strong goal commitments, it is the forming and holding of highly mandated links between situational cues and goal-directed behaviors that produce implementation intention effects. For the successful implementation of health goals this implies that people need to set and hold strong health goals and furnish them with implementation intentions to which they feel highly committed.

Is behavioral control through implementation intentions truly habitual? The neuropsychological literature reports that patients with a frontal lobe injury have problems with the conscious control of their actions (e.g., Shallice, 1982), whereas the control of habitual actions is not impeded. Lengfelder (1994) explored the assumption that implementation intentions automatize action initiation by employing the dual task paradigm described above (Brandstätter, 1992, Study 2) with a sample of frontal lobe patients. As expected, implementation intentions managed to speed up action initiation even with these patients. Most interestingly, this effect of implementation intentions was even stronger when patients showed a weak performance on the Tower of Hanoi problem - a classic measure of a person's aptitude for conscious action control. These findings support the argument that implementation intentions induce direct, automatic action control. Implementation intentions are an effective self-regulatory tool even, and in particular for, frontal lobe patients and should therefore be included in rehabilitation programs. Moreover, relying on implementation intentions as a self-regulatory tool seems to be crucial when a break-down of the conscious control of action is anticipated; for example, when people have to face strong emotional experiences, intensive ruminations, intricate problem solving, or strong pain, all of which are likely concomitant circumstances of acute and chronic illnesses.

Can implementation intentions break bad habits? The automatic action control associated with implementation intentions has an interesting implication for the control of unwanted habitual responses. When certain behaviors, goals, and cognitive concepts are repeatedly and consistently instigated in the same situational context, they fall under the direct control of the respective situational cues (Bargh and Gollwitzer, 1994). If people want to inhibit 
such cues, goals, or cognitive concepts, they may turn to implementation intentions as a self-regulatory tool. In this case, implementation intentions will have to link the critical situational cues to antagonistic behaviors, goals, and concepts. This should create competition between the unwanted habitual response and the aspired to antagonistic response. The competition should be won by the intended antagonistic response, when the link created by the implementation intention is stronger than the link established through repeated and consistent pairing of the critical situational cues with the habitual response. Gollwitzer and collaborators are currently exploring the inhibiting factors of implementation intentions on the suppression of the so-called automatic activation of stereotypes (i.e., the gender stereotype and the elderly stereotype). This line of thought seems particularly relevant for the suppression of bad health habits. For example, a person, who has formed the health goal of adhering to a low calorie diet, must not only focus on the initiation of goal-directed behaviors (i.e., eating low calories foods) but also on inhibiting relevant bad habits, such as indulging in chocolate and other high calorie foods when they are presented. For this purpose the person may form implementation intentions such as, "as soon as I see chocolate, I will ignore it!".

\section{Getting Started: Facilitative Effects of Implemental Mindsets}

The effects of implementation intentions we have discussed so far are very specific. They only relate to the particular situations and behaviors specified. However, forming implementation intentions should also have more general effects. As pointed out above, intensive involvement with planning the implementation of one's goals creates a so-called implemental mindset. The features of this special cognitive orientation also help people to act by alleviating the crucial problem of getting started. Often people fail to implement a goal even though the situational context would allow it because they experience doubts about the feasibility or the desirability of the goal. Numerous mindset experiments suggest that implemental mindsets suppress such doubts. As a consequence, people in an implemental mindset should more readily seize any goal-relevant opportunities.

Positive illusions. Gollwitzer and Kinney (1989) cued a group of university student participants into an implemental mindset by asking them to plan the implementation of a personal decision they had already made (e.g., to move from home, have a medical check-up). More specifically, participants had to divide this project into five steps, and to list when, where, and how they intended to initiate goal-directed actions for each of these steps (i.e., form implementation intentions). A second group of participants were cued into a deliberative mindset. These participants were asked to contemplate the pros and cons of an unresolved personal problem (e.g., should I move from home, should I have a medical check-up?). Subsequent to the mindset manipulations, both groups of participants were moved on to a supposedly second experiment, where participants had to work on an Alloy and Abramson type (1979) contingency learning task. A third group of participants (control group) immediately started to work on this task, which involved attempts to gain control over frequent but uncontrollable target light onset by either pressing or not pressing a button. Implemental mindset participants' illusion of control tended to be greater than that of control participants and was much greater than that of deliberative mindset participants.

Taylor and Gollwitzer (1995) extended this research by encompassing other indications of positive illusions, such as optimistic self concept (e.g., athletic ability, social 
self-confidence, self-respect) as well as perceived invulnerability to more or less controllable risks (e.g., addiction to prescription drugs and having a drinking problem versus losing a partner to an early death and developing diabetes, as rated by a similar college student sample). When using the same type of mindset manipulation, implemental mindset participants described their own personal qualities and skills more positively than they did those of the average college student, and they did this to a larger degree than both deliberative mindset and control participants. The same pattern of data emerged for perceived invulnerability to both more or less controllable risks. Finally, implemental mindset participants reported themselves to be in a better mood than both deliberative mindset and control participants. The differences in mood did not account, however, for the differences in self-perception and perceived invulnerability to risks.

These findings suggest that individuals in an implemental mindset are quite certain of the feasability of their goals. They believe themselves to be very capable, rather invulnerable to both more or less controllable risks and in control of uncontrollable action outcomes (see the study by Gollwitzer and Kinney). This abundant optimism associated with the implemental mindset should supress doubts about being able to reach a set goal and so favor the efficient initiation of goal-directed actions. As has been shown many times, optimism about the feasibility of goals - even if it is illusionary - leads to more successful goal achievement than pessimism (for reviews, see Bandura, 1991; 1997; Carver and Scheier, 1989; Oettingen, 1997; Taylor and Brown, 1988; Seligman, 1991).

It has been argued that unrealistic optimism about controllable health risks is counterproductive for setting health goals (Schwarzer, 1994; Weinstein, 1980; 1982). This makes sense, as a person who does not accept a risk will not protect herself by forming respective health goals. When people already have set health goals, however, being optimistic about avoiding health risks should feed into people's efforts to implement their goals like any other optimism does (e.g., illusion of control, high outcome expectation, strong self-efficacy expectation).

It appears, then, that involving oneself with the planning of set goals and thus working up an implemental mindset with its consequent optimism is a powerful self-regulatory tool. It remains an open question, however, whether people who are facing a severe health threat are also capable of working up optimism via implemental mindsets. In a recent study, we put severely depressed patients (mean $\mathrm{BDI}>28$ ) who were either out-patients or hospitalized into an implemental mindset by having them plan (in the way described above) the performing of a daily chore. When implemental participants were subsequently asked to gain control over frequent uncontrollable outcomes in a contingency learning task, they reported a striking illusion of control that substantially exceeded that observed in control participants and participants who had been cued into a deliberative mindset. It would seem, therefore, that implemental mindsets do create optimism effects even in people who are chronically pessimistic. This recommends implemental mindsets as a self-regulatory tool for people who have reason to have a pessimistic outlook on themselves and the world.

Unequivocal behavioral orientation. Continually deliberating the desirability of the chosen goal anew should hamper the efficient initiation of goal-directed actions as doubts about the goal's desirability might be raised. Therefore, it is interesting to ask whether the implemental mindset directs a person's thoughts away from the deliberative issue of estimating the expected value of the goal towards the implementational issues of when, where, and how to act on the goal. 
Gollwitzer, Heckhausen and Steller (1990) report two studies suggesting that implemental mindsets favor the processing of information relevant to executing a person's goals and hamper the processing of expected-value-related information. Planning apparently orients people towards issues of implementation as processing of implementation-related information becomes easier, whereas the opposite is true for expected-value-related information.

If participants who have started to plan the execution of a goal (e.g., to terminate an unhappy relationship) are forced to think about its expected value by being asked why they would pursue the chosen goal (Taylor and Gollwitzer, 1995; Study 3), they do not think equally about the pros and cons, but rather strongly favor pros over cons. In addition, they think more about implementation-related issues than about the expected value of the set goal. Apparently, planning discourages people from returning to the deliberation of a chosen goal by focussing them on both, the pros of their choice and the implied implementational issues. These findings should also apply to health goals: for example, a person, who has started to plan the implementation of the goal to stop smoking should develop an unequivocal behavioral orientation that makes redeciding more difficult.

\section{Completion of Goal Pursuit: Positive Effects of Implemental Mindsets and Implementation Intentions}

Volitional problems are not only associated with getting started. When the first steps towards goal achievement are successfully implemented, further obstacles may be encountered. First, people may have to step up their efforts when unexpected increases in task difficulties threaten successful task performance. Second, people may have to ward off distractions, because most situations allow for more than one goal pursuit; that is, people need to prevent the primary goal pursuit from being derailed. Third, if people fail at these problems, a further volitional problem arises: the interrupted goal pursuit needs to be resumed. Can planning alleviate these volitional problems?

Effort mobilization. Energization theory (Wright, 1996) holds that as perceived task difficulty increases, so does a person's effort - at least up to a certain point. This cutoff point describes a person's potential motivation and is reached rather early with unattractive tasks, but much later with attractive tasks. As implemental mindsets make people feel very positive about the expected value of their goals, it follows that people in an implemental mindset should reach the cutoff point comparatively later and therefore show high persistence in the face of difficulties.

But effort mobilization may also be achieved via implementation intentions. If a person anticipates the critical difficulty and links it to a behavioral response that implies heightened effort, the initiation of this behavior should be facilitated once the difficulty is encountered. In other words, an implementation intention that links an anticipated difficulty with the behavioral response associated with high effort should lead to effort mobilization in the presence of this difficulty. For example, a person with the goal to abstain from drinking alcohol may form implementation intentions to politely but firmly reject a drink when it is offered by the host of a dinner party.

Warding off distractions. Kuhl (for reviews see Kuhl and Beckmann, 1985; 1994) has applied his theory of action control to the issue of warding off distractions. The theory distinguishes a number of different mental strategies (e.g., attention control, emotion control), which are assumed to effectively shield a person's ongoing goal pursuit from 
distractions stemming from potential alternative pursuits. Action-oriented people are found to use these strategies more effectively than state-oriented people, as the latter tend to become wrapped up in ruminations about past failures and desired successes or in the deliberation of a decision.

Can planning also strengthen a person's shielding off an ongoing goal pursuit? Gollwitzer (1991; Chapters 4 and 7) reports experiments where participants were placed into an implemental or deliberative mindset and then asked to work on certain cognitive tasks. In the first study, a so-called central-incidental memory task was employed, in later studies displays were presented that carried modified Müller-Lyer-figures. Implemental mindset participants showed a comparatively worse recognition performance for peripherally presented incidental information, and the implemental mindset produced more illusions associated with a narrow field of attention. The results of these studies suggest that planning creates a certain closed-mindedness which is based on a narrow field of attention. This effect of planning transported via the implemental mindset should facilitate warding off all kinds of distractions (even unanticipated distractions), because the goal currently pursued commonly takes center stage, whereas distractions originate from the periphery.

But planning can also focus on particular anticipated distractions. Implementation intentions that specify a feared distraction as the situational cue to which a protective response is linked should provide an effective strategy for escaping these distractions. This has been shown some time ago by Patterson and Mischel (1976) who equipped children with specific plans to escape the temptations of "Mr. Clown Box" while they were trying to complete the boring tasks of putting as many pegs into a pegboard as possible. Mr. Clown Box asked the children, to disrupt their tasks and press his nose, and displayed various distractive stimuli (e.g., attractive toys in an illuminated window). When the children had formed temptation-inhibiting plans ("When Mr. Clown Box says to look at him and play with him, then I just won't look at him, and will say, 'I am not going to look at Mr. Clown Box!"'), they were very successful in warding off the distractions of Mr. Clown Box and showed an enhanced pegboard performance as compared to control children who were not equipped with such a plan. Interestingly, so-called task facilitative plans ("When Mr. Clown Box says to look at him and play with him, I'll just look at my pegboard, and say, 'I am going to look at my work!'") did not show any effects.

Schaal (1993) recently replicated these findings with adults who were asked to solve as many arithmetic problems presented on a computer screen as possible. These problems were simple but demanded much attention. On top of this screen a TV-terminal was mounted showing very attractive award winning commercials in random intervals. Participants were requested to form disruption-inhibiting implementation intentions ("As soon as a commercial comes on, I will ignore it!") or task-facilitating implementation intentions ("As soon as a commercial comes on, I will concentrate on my work!"). The control participants solely set the goal not to let themselves be distracted from working on the arithmetic problems (i.e., they formed a goal intention). As in the Patterson and Mischel study, the way in which the response part of the implementation intention was phrased mattered. Distraction-inhibiting implementation intentions were superior to both task-facilitating implementation intentions as well as to goal intentions. Future research may clarify why distraction-inhibiting implementation intentions are more effective than task-facilitating implementation intentions.

It appears, therefore, that distraction-inhibiting implementation intentions could be very powerful self-regulatory tools for people who have set themselves health goals, in 
particular when the successful pursuit of these goals is threatened by frequent distractions. Think of the person who has formed the health goal of eating low-calorie food. Any table that holds tastier high calorie foods provides a host of distractions. Forming distraction-inhibiting implementation intentions should provide a chance to stick to the goal of eating low-calorie food.

Resumption of disrupted goal-pursuit. Many goal pursuits are long-lasting and therefore often get interrupted. To resume the disrupted goal pursuit is particularly difficult when many incomplete goal pursuits rival each other. Such conflict may produce inactivity with all of the goal pursuits at hand. The question addressed in a recent study was whether placing people in an implemental mindset reduces such conflict.

Pösel (1994) asked participants to start two delayed goal pursuits by writing a letter for each of these projects. However, when participants had addressed each of the two letters, they were disrupted and put in an implemental, deliberative, or no mindset by a different experimenter. When participants returned to the first experimenter, they were allowed to complete the incomplete letters which were still sitting on the desk. Pösel observed that there was no difference between participants with respect to the latency with which participants grabbed one of the letters. However, the implemental mindset participants started to write faster as compared to the deliberative mindset and the control group. Apparently, the implemental mindset helps participants to shield the resumption of an interrupted task from competing unfinished business. This finding parallels the observations reported in the subsection (above) on warding off distractions, which suggests that implemental mindset participants are characterized by a narrowed field of attention.

For people who have set themselves health goals, conflicts between unfinished business may be prevalent and hinder resumption. For instance, the goal of exercising regularly may conflict with other unfinished business (e.g., professional tasks). Being in an implemental mindset should reduce such conflicts and thus focus the individual's mind so that both projects can be pursued effectively (in turn or successively) without feeling disturbed by the other project.

\section{Conclusions and Prospects for Future Research on Goal Implementation}

Given that a person feels highly committed to a goal, does planning how to achieve this goal help goal attainment? Our analysis strongly suggests that people can derive additional volitional benefits from planning. First, initiating goal-directed behaviors is facilitated, because planning creates a perceptual readiness which guides people's attention towards relevant opportunities and goal-related means. In addition, it sets up a special behavioral readiness to respond effectively once these opportunities and means are encountered. Illusory optimism and the unequivocal behavioral orientation associated with planning also suppress disfunctional doubts about the goal's feasibility and desirability. Second, bringing an initiated goal pursuit to successful completion is facilitated, because planning helps to mobilize effort in the face of difficulties and to ward off distractions. Moreover, if disruptions to goal-directed actions occur, planning furthers effective resumption.

The experiments presented have demonstrated that many of the beneficial effects of planning are based on the cognitive features of the implemental mindset. The task that leads to the implemental mindset is planning the execution of goal-directed behaviors. The form of planning we have used to induce implemental mindsets has been committing oneself to plans that specify when, where, and how the most important behavioral steps 
of goal attainment are to be executed; all of this has been requested with projects which demand intensive planning. Future research may want to address the question of whether other forms of planning are equally suited to produce implemental mindsets. In addition, health psychologists may want to explore how people who have set themselves health goals are best taught to produce implemental mindsets so that they can be used as an effective self-regulatory tool in everyday life.

The experiments discussed have also demonstrated that many of the benefical effects of planning are based on the various cognitive processes originating from implementation intentions. The strength of these effects should be dependent on the strength of the links that are created between anticipated situational cues and goal-directed behaviors. The Seehausen et al. (1994) experiment reported above hints at commitment or strong willing as a crucial variable of strengthening these links ("I really want to stick to my implementation intention as specified!"). Apparently, the strength of the link specified in an implementation intention is dependent on the strength of willing a person manages to mobilize when she connects situational cues with goal-directed behaviors. This is why strong implementation intention effects can only be observed on the basis of strong goal intentions: one cannot expect strong acts of willing on the basis of weak goal intentions.

Future research may want to address whether the strong implementation intention. effects observed in the present research are dependent on concretely specifying the situational cues and the respective behaviors. Perhaps more abstract definitions would suffice. For the health psychologist it will be important to not only focus on strengthening the commitment to set health goals but also to teach people to furnish their health goals with strong implementation intentions.

\section{THE EMERGENCE OF GOALS}

In the action phase model goals are conceived of as transformed wishes in the sense that they are transformed into a binding commitment. The action phase model also specifies the criteria that predict which of the many wishes and desires a person holds are most likely to be turned into goals. It is assumed that feasible and attractive wishes have the best chance, but the model does not explain how wishes are turned into binding commitments and thus cannot specify beneficial self-regulatory procedures that help people to move from wishes to goals.

One might argue that wishes by themselves are guiding people's behaviors as long as they are describing attractive, desirable end-states. A closer look at this proposition, however, reveals that wishes (e.g., "I wish I had a slim body", "I wish I would be a non-smoker", "I wish I had better health") are not just ineffective in guiding outcome-related behaviors, they even hinder the attainment of the desired outcomes. In the next section, we will report a series of studies that attest to the harmful quality of indulging in positive fantasies about one's personal future, that is, in one's wishes and desires.

\section{The Harmful Effects of Indulging in Positive Fantasies}

Researchers commonly analyze people's thinking about the future in terms of expectations, that is, judgments about the likelihood of future events. Whether these expectations are conceptualized as control beliefs, self-efficacy beliefs, outcome expectations, or 
expectations of future life in general (Bandura, 1997; Scheier and Carver, 1992; Seligman, 1991; Taylor and Brown, 1988), they are held to reflect a person's past experiences and therefore are considered to be powerfil predictors of a person's future. Thoughts about the future, however, do not necessarily have to be beliefs about how likely or unlikely a certain desired event will occur, or that a certain behavior will be performed. People can also spontaneously imagine their desired successes, experience them in their minds' eye, and construct and reconstruct their mental images of future events at their liking; in their daydreams they fancy masterful performances and blissful experiences. Fantasies more easily escape the grip of reality than expectations, because fantasies are not constrained by the cognitive mechanisms that make people acknowledge factual information (Klinger, 1971; 1990; Singer, 1966). Accordingly, individuals may indulge in spontaneous positive fantasies about the future, even though a critical analysis of past performances or assessing the statistical likelihoods would lead to low expectations of success.

But how does fantasizing about one's personal future affect a person's readiness to act on her desires? Positive fantasies of success constitute an anticipation of already having reached the success and thus an anticipatory consumption of the various associated positive consequences or experiences. In a positive fantasy a person may vividly experience the desired future event and may color it more brightly and joyfully than reality would ever permit. Therefore the need to act may be diminished and the thorny path towards enacting the fantasy overlooked. Accordingly, no action plans on how to achieve the fantasies should be formed and no precautions for unforeseen hindrances should be taken. This should reduce the chances of success as a lack of action plans has been linked to decreased performance (see above). In summary, because positive fantasies imply anticipatory consumption of success, no need to act towards implementing the success is experienced and no concern with how to act originates. All of this should hinder successful performances. In comparison, negative fantasies should prevent anticipatory consumption and thus should not be associated with the mental consequences described above and the respective negative performances. An overweight person, for example, who indulges in positive fantasies of losing weight and obtaining a slim body should be less prepared for the necessary actions and attaining the desired outcomes than an overweight person who allows for thoughts about the burden of her overweight body and the hardships of dieting.

Various correlational studies were conducted to test these hypotheses. Different life domains were chosen that affect people's living a productive and healthy life (i.e., romantic and professional success, recovery from chronic and acute illness, and weight loss; Oettingen, 1996; 1997). In all of these studies the positive nature of participants' fantasies about the future were assessed long before (up to four years) the respective successes were measured (e.g., getting a job).

Participants' expectations about achieving the desired success were also assessed, to set the predicted negative relation between fantasies and success against the classic finding that thinking about the future in terms of expectations relates positively to success (for a summary, see Bandura, 1997). Because expectations (in contrast to fantasies) are beliefs about the likelihood of future events which reflect a person's performance history, high expectations of success signal that a given desired event is likely to be attained and thus stimulate people's efforts to realize the desired success.

Weight loss. Oettingen and Wadden (1991) assessed expectations of weight loss as well as weight and food related fantasies in 25 obese women who had enrolled in a weight 
reduction program. A semi-projective procedure was used to assess the positivity of patients' fantasies. Each patient was asked to imagine herself vividly as the main character in four weight and temptation-related scenarios. Two stories were designed to elicit fantasies about the participants' weight loss, whereas the other two stories described encounters with tempting foods. Each story had an open ending which participants were asked to complete in writing by describing the stream of thoughts that occurred to them. Immediately after describing the mental images, participants rated the positivity of their fantasies as well as their imagined body shape. Weight loss was measured three times, at 4 months, 1 year and 2 years later.

Both, fantasies and expectations, predicted weight loss, albeit in opposite directions. After 1 year, patients with positive fantasies lost about 11 kilogramm less than those with negative fantasies, and patients with positive expectations lost about 12 kilogramm more than those with negative expectations. After 2 years, the respective differences were 12 and 15 kilogramms. The observed results stayed unchanged when participants' weight loss aspirations (in pounds) and the expected value of reaching the aspired weight loss were covaried. The results demonstrate that indulging in positive fantasies of getting a slim body and resisting food temptations hinders the actual attainment of weight loss.

A closer look at the individual fantasies participants reported revealed that participants with positive fantasies daydreamed that weight loss had occurred without much effort. For example, one participant who rated her fantasies as very positive imagined herself in a bathing suit being critically appraised by her friends: "I'll be shining!". Participants with negative fantasies, however, created food and weight-related problems in their minds' eye and simulated solutions, thus preparing themselves for upcoming hindrances and unforeseen obstacles.

Recovery from chronic and acute illness. In a conceptual replication of the weight loss study, out-patient children suffering from chronic asthma and gastrointestinal disease as well as cancer (leukemia and lymphoma) were contacted, and fantasies, expectations, and disease activities were measured (see Oettingen, 1996; 1997). Positive fantasies concerning patients' future lives were assessed by 12 scenarios which pertained to the domain of health, interpersonal relations, and school achievement. A typical scenario read: "Imagine you have been invited to sleep over at a friend's house, but since you have been sick for the past couple of days, your mother calls the doctor to see if you are well enough to go. She hangs up the phone and...". After the children had completed the scenarios in writing, they rated the positivity of their images. Expectations were operationalised by using the Children's Attributional Style Questionnaire, which assesses to what extent hypothetical positive events are perceived as stable, global, and internal when compared to negative events (Seligman, Peterson, Kaslow et al., 1984). An optimistic explanatory style conveys a person's sense that she will eventually be able to deal with the situation at hand and thus indicates positive expectations.

When disease activity for chronic illnesses (i.e., peak flow measures for asthmatic children and prescription scores for children with gastrointestinal disease) were assessed several months later, and corrected for the respective measures at the time of the assessment of fantasies and expectations, the pattern of results was the same as in the weight loss study. The more positive the children's fantasies were, the worse their disease activity; the reverse relationship was again observed for expectations. With respect to the children with leukemia and lymphoma, we asked the physician in charge to rate probability of survival at two points in time: when fantasies and expectations were obtained and four years 
later. Positive fantasies in response to health scenarios hampered recovery rate, whereas expectations showed a close to zero correlation.

In summary, these results suggest that indulging in positive fantasies about the future is not only maladaptive for health promoting and disease preventing behaviors such as losing weight, but also for the recovery from chronic and acute illnesses. For the health psychologist it seems crucial, therefore, not to support people's fantasizing about positive health behaviors and outcomes, but to find ways of transforming these positive wishes into strong goal commitments. Before we turn to measures that effectively serve this purpose, we would like to report further evidence that speaks to the harmful effects of mere fantasizing - this time in the interpersonal as well as professional domain with larger samples and different health-relevant dependent variables.

Romantic success. Students who had crushes on fellow students of the opposite sex, but who were not yet going out and not yet involved with them, were tested for their fantasies about what might happen to them and their "crushees" in the future (see Oettingen, 1996; 1997). Participants again had to fantasize a number of prepared incomplete scenarios to completion, and rate the positivity of their fantasies; in addition their expectations of success were assessed. After several months participants were asked whether they succeeded in getting involved with their "crushee." Students with positive fantasies were less successful than those who did not indulge in positive fantasies; again, participants with positive expectations were more successful than those with negative expectations. This pattern of results was observed for men and women and remained even when the incentive value of becoming involved was statistically controlled for.

Professional success. Students who were completing their university education and prepared to enter the job market were asked to report about their spontaneous positive and negative fantasies related to the upcoming transition into work life (see Oettingen, 1996; 1997). They then had to indicate how often they recently had experienced such positive and negative fantasies, respectively. From these reports we constructed an index that captured the relative frequency of positive over negative fantasies. As in the other studies, participants were also asked to report their expectations of finding a job. Two years later, participants were contacted again and asked how many jobs they had been offered and what their present salary was. Positive fantasies hampered professional success as measured by both variables, whereas high expectations facilitated it. This pattern of data held even after the incentive value of getting a job was statistically controlled for.

Summary. The presented studies reveal that positive thinking about the future that takes the form of indulging in positive future events is prone to be counterproductive. Self-help books (e.g., Kirk, 1994; Simonton, Matthews-Simonton and Creighton, 1978) that advise the health conscious person to think positively about her health (or a slim body, athletic fitness, successful dieting and exercising), hoping to induce health promoting responses and to reduce health compromising responses are therefore likely to fail. Dwelling on positive fantasies inhibits rather then promotes self-regulation.

Apparently, the self-help literature has failed to make the distinction between thinking about the future in terms of spontaneous fantasies versus expectations. It correctly took notice of repeated empirical demonstrations of the beneficial effects of high expectations of success. As these are based on a person's performance history, they are certainly powerful predictors of behavior, but cannot be changed at will and thus do not qualify as an 
ubiquitous self-regulatory tool. To increase expectations of success one needs to change one's performance history; simply fantasizing about great performances will not suffice. On the other hand, fantasizing is not restricted by reality, and can therefore be used excessively. No wonder, then, that self-help books focus on the fantasy-type of positive thinking: it is readily accessible and thus seduces one to think of it as a potential selfregulatory tool. The problem is that the effects on behavior and success are just opposite to what is known of positive thinking in terms of expectations. Thus, the health psychologist must encourage the transformation of positive fantasies about the future into binding health goals. In the next section, we will explore mental procedures that instigate this transformation process.

\section{The Transformation of Positive Fantasies into Goals}

Why were positive fantasies about the future more harmful to success than negative fantasies? Participants with positive fantasies failed to perceive the occurrence of hardships in their minds' eye and did not feel a need to act towards realizing their fantasies. This speculation is supported by additional data collected in the context of the romantic and professional success studies described above. Indeed, in the romantic success study, participants with positive fantasies reported not having made an effort to confess their infatuation to the crushee; instead, they preferred to fancy him or her from a distance. Participants with positive fantasies in the professional success study reported to have sent out fewer job applications than participants with negative fantasies; at the same time, they reported having refrained from making commitments that potentially would conflict with starting the desired job and having already prepared themselves for changes in their private relationships that would result from accepting the hoped for job offer. Apparently, participants generating positive fantasies took their successes for granted. They presumptuously perceived themselves as already having obtained the desired job offer, and thus failed to tackle the adverse reality that needs to be changed if success is actually to be attained.

These observations suggest an answer to the question of how positive fantasies about the future might be stripped of their consumptive qualities and turned into binding goals. If positive fantasies are mentally contrasted with reflections about the negative reality that stands in the way of fantasy fulfilment, a person should finally feel a need to act. Positive fantasies are now experienced as something to be achieved in real life and thus should no longer allow indulgence and premature consumption. Moreover, whereas reflections on the negative reality point to the necessity to act and provide clues on how to actually implement fantasies in real life, positive fantasies give action the necessary direction. In other words, mentally contrasting the positive fantasies with reflections on the negative reality should turn the fantasies into behavioral goals. For example, an overweight person who contrasts her positive fantasies with reflections about the respective negative reality (e.g., her impulsive eating behaviors, her liking of high-calorie foods, social drinking, and her distaste for physical exercise), should no longer be able to indulge in her fantasies of a slim body, because they appear as something to be obtained in real life.

One further crucial precondition is required. When people start to experience a positive fantasy as something to be realized and the negative reality as something to be changed, they must also acknowledge the probability that this can be achieved. Accordingly, their expectations of success should ultimately determine whether mental contrasting leads a person to adopt binding goals. Only if subjective probabilities (i.e., expectations of 
success) are high and the person sees a reasonable chance to reach her desired fantasies in real life, should she commit herself to the respective behavioral goals. If the subjective probabilities are low, the person faces the unattractive option of having to dismiss her fantasies. As mentally contrasting has turned these fantasies into something to be achieved, they can no longer be consumed and enjoyed presumptuously; and if the prospects of actually achieving them are bleak, it does not make sense to attempt their realization.

On the contrary, a person who enjoys her positive fantasies without contrasting them with reflections on negative reality does not experience a need to act and therefore will not consider subjective probabilities of success when acting. Such a person should not show intensive goal striving when expectations are high, and should not show disengagement when expectations are low. As compared to the individual who mentally contrasts fantasy and reality, there should be no difference in her engagement regardless of whether subjective probabilities of success are high or low. Similarly, a person who only dwells on the negative reality should also fail to set herself goals, because positive fantasies cannot give action the necessary direction and reality is not experienced as something to be changed. Subjective probabilities of success should again not be considered, and engagement in any of the respective behaviors should not reflect the strength of expectations. In other words, people who only dream and people who only worry should not act according to their subjective probabilities of success.

This line of thought implies that people who are requested to mentally contrast their positive fantasies with reflections on the negative reality should act according to their expectations. In case of positive expectations, strong goals should emerge and intensive goal pursuit should be observed when the situational context allows for it. In case of negative expectations, people should decide to stay passive and therefore no goal pursuit should be observed even when people face good opportunities to act. Pure dreamers and pure worriers, in contrast, should neither set themselves goals when expectations are high nor intentionally refrain from goal-pursuit when expectations are low. When relevant opportunities arise, they are merely pulled by their positive fantasies or pushed by their worries about the negative reality. Therefore a middle level of engagement with respect to relevant actions (i.e., to change reality in the direction of fantasy fulfilment) should be observed irrespective of the level of subjective probabilities of success.

In a series of experiments, these ideas on the emergence of goals were tested. In each of the studies a fantasy-reality contrast condition was established and compared to both a positive fantasy only group and a reflections on the negative reality only group. The fantasy only group was established by inducing participants to excessively fantasize about a desired positive future. The reality only group was created by requesting participants to intensely ruminate about aspects of the present negative reality that stands in the way of fantasy fulfilment. In the fantasy-reality contrast condition participants were encouraged to face the contradiction between the desired future and the experienced present reality. In all studies participants' readiness to realize their positive fantasies about the future was assessed; this was done immediately after the experimental manipulations and again some time later (up to two weeks) to provide participants with ample opportunities to get started. Finally, in each of the studies the fantasies generated by participants covered a different health-relevant domain of life.

Interpersonal relationships. In a first experiment (see Oettingen, 1996; 1997), female students were asked to name the interpersonal matter that was presently most important to them (e.g., participants mentioned matters such as settling a conflict with my partner, 
getting to know somebody) and to judge the likelihood that it would result in a happy ending. Then they were asked to list positive aspects of the happy ending (e.g., feelings of being cared for, being needed) and negative aspects of the present reality that stand in the way (e.g., being impulsive, being shy). In the fantasy-reality contrast group participants had to select two aspects of both, the happy ending and the negative reality. To achieve a fantasy-reality contrast, participants were asked to alternate between generating spontaneous thoughts and images for positive aspects of wish fulfilment and negative aspects of reality, beginning with a positive aspect. Thus two positive and two negative aspects had to be reflected on intermittendly. In the fantasy only group participants had to pick four positive aspects of wish fulfilment and indulge in respective fantasies; while in the reality only group, participants had to pick four negative aspects of reality and ruminate about them. Immediately afterwards participants were asked by use of a mood questionnaire how energized and active they felt, and two weeks later they were asked if and when they had acted to realize their fantasies.

Participants felt most energized and initiated actions earliest in the fantasy-reality contrast group, when they held high expectations of success; in the case of low expectations participants felt least energized and initiated actions most sluggishly. On both of these dependent variables the other two groups, the fantasy only and the reality only group, scored in between regardless of whether participants held low or high expectations. The results of various additional statistical analyses confidently ruled out that this pattern of data might be a consequence of a change in the level of expectations or expected values caused by the different mental manipulations.

For the health psychologist who wants to help people to turn their wishes towards eliminating bad health habits (e.g., smoking too much) and establishing effective health goals, these findings have important implications. First, it does not suffice to intensify people's fantasies about a positive future of having overcome this problem. Second, it does not help to make people dwell on their present shortcomings in dealing with the problem. Instead, people need to be encouraged to mentally contrast their positive fantasies with reflections on the respective negative reality. However, this needs to be preceded with strengthening people's expectations of success. Many approaches of boosting people's expectations could be used (e.g., pointing out past successes, having people vicariously experience successes of similar others, praise by the therapist, or simply providing detailed information on how to effectively deal with the problem; see Bandura, 1986). The present study is concerned with fantasies originating from ongoing concerns. But perhaps new fantasies can also be turned into goals by the mental procedure of contrasting positive fantasies with reflections on the negative reality. This would have important implications for instigating health goals because it would allow infatuations (e.g., with fashionable trends such as eating Japanese foods, taking fitness vacations, or using the bike instead of the car) to be translated into a binding goal of regular dieting or exercising. The following study considers this issue.

Getting to know an attractive stranger. In a second experiment (see Oettingen, 1996; 1997) the same new concern, an infatuation with a stranger, was created for all participants. The cover story told the participating female students that daydreams about getting to know strangers would be at issue. Then participants were shown a picture of an attractive young man, supposedly a young researcher at the institute. Participants had to indicate their expectations in terms of the probability of successfully getting to know this person if they had the chance. Then participants went through the same procedures as in the preceding study. This time the aspects of fantasy fulfilment pertained to how enjoyable it would be 
to get to know this person, whereas the aspects of the negative reality pertained to what would stand in the way of getting to know him (e.g., being shy). Again, a fantasy-reality contrast group, a positive fantasy, and a negative reality group were created. The crucial dependent variable in the present study was the extent to which participants felt committed to meeting this person (i.e., how disappointed participants would feel, if they had no success). Results were measured at the end of the experiment and one week after.

The pattern of results match that of the preceding experiment and it was more pronounced after one week than immediately after the experiment. Participants with high expectations in the fantasy-reality contrast group felt as strongly committed to get to know the person one week later as at the end of the experiment. For all the other groups the originally experienced infatuation with the idea of getting to know the young man did not persist over time. Participants with low expectations in the fantasy-reality contrast group were again the ones who completely disengaged from the fantasy. After one week they reported no disappointment in relation to not being able to get to know the young man.

Apparently, infatuations can be used to create binding goals. This means that infatuations with fashionable health-promoting behaviors such as riding chic bikes and eating nouvelle cuisine could also be turned into lasting goals by fantasy-reality contrasting mental endeavours. However, more often than not, the essence of setting health goals pertains to the integration of goals. For example, switching from a high-cholesterol to a low-cholesterol diet means integrating the new goal (i.e., eating low cholesterol food) into ongoing goals (e.g., relaxing with one's colleagues at lunch time in the cafeteria which serves unhealthy food). Does the self-regulatory tool of contrasting positive fantasies with reflections on the negative reality also promote goal setting under such circumstances?

Combining work and family life. Participants were female doctoral students who were approaching a critical age for being able to have children (see Oettingen, 1996; 1997). They were asked to produce positive fantasies about their professional and private lives several years from now, let these mental images pass in front of their minds' eye, and then describe them in writing. Most of the participants daydreamed about having both a professional career and a child. To measure expectations of success, participants were requested to rate their confidence that their fantasies would come true. Thereafter the fantasy-reality contrast, the positive fantasy, and the negative reality groups were established. This time a different procedure was used than in the preceding studies. All participants had to read lively reports from working mothers who described the daily hazzles of combining work and family life. In the fantasy-reality contrast group participants were encouraged to read these statements carefully and to create associations to these negative reports. This way participants who had just fantasized positively were forced to contrast these fantasies with the respective negative reality. In the fantasy only group participants were encouraged to trivialize the mothers' complaints; we told participants that the mothers came up with these statements as an excuse, that is, they were trying to conceal personal problems. Participants were asked to find out what each mother was trying to conceal; it was hoped that this way participants would not take the reported negative reality seriously. In the reality only group participants were induced to ruminate about the negative reality by being asked to relate the mothers' reports about the experienced hardships to participants' own problems, that is, to the question of why they had failed to start a family.

Two weeks later participants were asked how committed they were to the goal to combine work and family life, how much effort they would be willing to exert towards achieving this goal, and whether they had started to think about the implementation of 
this goal. The same pattern of results emerged as observed with the previous experiments. Participants in the fantasy-reality contrast group who had high expectations of success again showed the strongest indications that they now had adopted a firm goal of combining work and family life (i.e., they reported the strongest feelings of commitment, the highest willingness to exert effort, and the highest frequency of relevant mental simulations), whereas participants with low expectations in the same group showed the least indications. Participants in both the positive fantasy only and the negative reality only group scored in between whether they held high or low expectations of success.

Summary. In each of the three experiments presented, participants with high expectations in the fantasy-reality contrast group showed immediate and long-term responses that are commonly found with people who have already set themselves goals (i.e., participants felt energized, they felt committed to attaining the desired outcomes, they planned the implementation of these outcomes, and initiated relevant actions without delay). Apparently, the mental contrasting of positive fantasies about the future with reflections on the negative reality makes people with high expectations turn their fantasies into goals. This mental contrasting thus qualifies as a self-regulatory tool for the transformation of a person's wishes and desires into goals.

Moreover, the mental contrasting procedure seems to be applicable for all kinds of desires: desires that people have been fantasizing about for quite a while (see the first experiment on interpersonal relationships), desires that arise on the spur of the moment (see the second experiment on infatuation), and for complex desires which entail fantasies about the integration of competing life themes (see the third experiment on combining work and family life).

\section{Conclusions and Prospects for Future Research on Goal Emergence}

It is important to remember that the self-regulatory tool of mental contrasting yields the opposite results for people who have high versus low expectations. It is only for people with high expectations that mental contrasting leads to goal emergence, for people with low expectations, a pronounced passivity is the result. For health goals to arise it seems important, therefore, to first strengthen people's expectations of success. For instance, if stress coping is at issue, people should be first taught (or should teach themselves) about the basic techniques of stress management in order to acquire a strong sense of competence (i.e., high expectations) with respect to coping with stress.

A further implication pertains to people who only ruminate about the negative aspects of reality and thus might be caught up in a depressed state of mind. Using the selfregulatory tool of mental contrasting with these people involves explicitly fostering the intrusion of positive fantasies. If these efforts to intersperse positive fantasies into their negative ruminations are successful, the mental contrasting procedure should lead to the emergence of goals and consequently alleviate the depressive state of mind: Goals are known to provide meaning (Emmons, 1986; Frankl, 1959), and efforts to attain the goal are associated with optimistic expectations (Taylor and Gollwitzer, 1995).

The reported findings make another point that is not directly related to goal emergence, but is relevant to increasing people's knowledge and procedural competence about how to effectively perform health promoting and disease preventing behaviors (e.g., programs on stress coping, healthy nutrition). The reported experimental findings suggest that people do not consult their expectations of success when they are wrapped up in positive 
fantasies or lost in ruminations on the negative reality. Therefore even if programs designed to increase people's competence are successful, they may not affect people's actual health behaviors. For example, an increase in competence (e.g., how to adhere to a low cholesterol diet) should yield respective behaviors only when people have contrasted their positive fantasies (e.g., about a long productive and healthy life) with reflections on the negative reality (e.g., the present poor health condition and bad health habits).

From an applied perspective it will be important to explore how the contrasting procedure can be induced most effectively. Contrasting positive fantasies about the future with reflections on the negative reality forces people to either set the goal to implement the fantasy or to forget the fantasy, and, therefore, contrasting should be experienced as aversive. As a consequence, it seems necessary to explicitly encourage people to contrast and discourage them from dreaming or ruminating. In positive fantasizers one has to disrupt the fantasies by pointing to the negative reality and by discouraging the fantasizers " rationalizations (e.g., downward comparisons, dehumanization of people who provide negative feedback) that down play this negative reality. For ruminators, on the other hand, it is important to instill lively positive fantasies and to intersperse them into their repetitive ruminations.

Health psychologists might also want to know how often the contrasting procedure has to be applied to induce stable goals. In the present experiments one application was enough to produce long lasting effects and thus stable goals. Repeated applications were not necessary, but this may not be so in real life. Also, some people might be less suited to benefit from the mental contrasting procedure. It is possible that visualizers (e.g., Horowitz, 1978) find it more difficult to apply the described contrasting procedure than verbalizers, because it is easier for visualizers to protect their fantasies from the critical objections stemming from reality.

Finally, future research on the emergence of goals should also address the issue of setting avoidance goals. In the experiments presented above the contrasting procedure was employed to induce approach goals only (e.g., resolving an interpersonal conflict). How would the contrasting procedure have to be restructered to foster the emergence of avoidance goals (e.g., to stay away from high calorie foods or alcohol)? In other words, is the contrasting procedure also applicable to promoting goals that specify the avoidance of health compromising behaviors? Oettingen (1997) suggests contrasting negative fantasies about the future (e.g., developing an overweight body, looking ugly and feeling horrible) with reflections on the positive reality (e.g., the present relatively slim and healthy body, looking nice and feeling well). Again, the crucial prerequisite for goals to emerge has to be kept in mind. One has to ensure that people have high expectations of success, which should relate this time to the likelihood of avoiding the unwanted future state. Accordingly, one has to teach people efficient ways of avoiding high calorie foods and alcohol before contrasting their negative fantasies about the future with reflections on the positive reality. Results from research on fear appeals are in line with this emphasis on high expectations. Scaring people by pointing to the negative consequences of their health compromising behaviors stimulates change only if reassuring instructions on how to avoid the danger are also added to the threatening message (Leventhal, 1970; Rogers, 1983).

\section{GENERAL CONCLUSION}

Modern goal theories make the claim that a person's behavior is not solely determined by motivational variables (expectations, values). The self-regulatory strategies people 
employ are said to make an additional contribution in the sense that a strong motivation can be enhanced by volition. This has been exemplified in the present paper by analyzing how effectively implemental mindsets and implementation intentions help people overcome classic problems of goal pursuit, such as initiating goal-directed actions and bringing them to a successful conclusion. Implemental mindsets and implementation intentions trigger various cognitive processes (e.g., perceptual and attentional processes) which in turn facilitate successful goal pursuit. As a consequence, it is suggested that people who have set themselves health goals may in a self-regulatory effort, actively create implemental mindsets and form implementation intentions which in turn trigger passive cognitive processes that foster goal achievement. In this way, the willful act of forming implementation intentions puts the individual's goal pursuit on automatic pilot.

Modern goal theories are mute to the question of how goals emerge. There has been recent theorizing on this issue, however, that focuses on the manner in which people think about the future. Assuming that a person's wishes and desires are the substance from which goals grow, one might expect that intensifying wishes and desires by positive fantasizing is the prominent route to goal emergence. The research discussed in the present manuscript clearly contradicts this view by demonstrating that positive fantasizing about desired outcomes (e.g., weight loss) has adverse effects. People's positive fantasizing about their wishes and desires can, however, promote goal emergence, if it is contrasted with reflections on negative aspects of the present reality. This mental contrasting procedure qualifies as a powerful self-regulatory tool for people who would benefit from setting themselves stable health goals.

\section{Acknowledgments}

The studies described in this paper and its preparation were supported in part by research grants and awards from the German Science Foundation, the Humboldt Foundation, and the Max Planck Society. We thank Charles Abraham, John Bargh, and two anonymous reviewers for their helpful comments on an earlier draft of this article.

\section{References}

Ajzen, I. (1985). From intentions to actions: A theory of planned action. In J. Kuhl and J. Beckman (Eds.), Action control: From cognition to behavior (pp. 11-39). New York: Springer.

Alloy, L.B. and Abramson, L.Y. (1979). Judgment of contingency in depressed and nondepressed students: Sadder but wiser? Journal of Experimental Psychology: General, 108, 441-485.

Bandura, A. (1977). Self-efficacy: Toward a unifying theory of behavioral change. Psychological Review, 84, 191-215.

Bandura, A. (1986). Social foundations of thought and action: A social cognitive theory. Englewood Cliffs, NJ: Prentice Hall.

Bandura, A. (1991). Self-regulation of motivation through anticipatory and self-reactive mechanisms. In R.A. Dienstbier (Ed.), Nebraska Symposium on Motivation: Vol. 38. Perspectives on motivation (pp. 69-163). Lincoln, NE: University of Nebraska Press.

Bandura, A. (1997). Self-efficacy: The exercise of control. New Yotk: Freeman.

Bandura, A. and Schunk, D.H. (1981). Cultivating competence, self-efficacy and intrinsic interest through proximal self-motivation. Journal of Personality and Social Psychology, 41, 586-598.

Bargh, J.A. (1982). Attention and automaticity in the processing of self-relevant information. Journal of Personality and Social Psychology, 43, 425-436.

Bargh, J.A. (1992). Does subliminality matter to social psychology? Awareness of the stimulus versus awareness of its influence. In R. Bomstein and T. Pittman (Eds.), Perception without awareness (pp. 236-255). New York: Guilford Press.

Bargh, J.A. (1994). The four horsemen of automaticity: Awareness, intention, efficiency, and control in social cognition. In R.S. Wyer. Jr. and T.K. Srull (Eds.), Handbook of social cognition (2nd ed.). Hillsdale, NJ: Erlbaum. 
Bargh, J.A. and Gollwitzer, P.M. (1994). Environmental control of goal-directed action: Automatic and strate(ic Vol 4l. Integrative view's of motivation, cognition and emotion (pp. 71-124). Lincoln, NE: University of Nebraska Press.

Brandstätter, V. (1992). Der Einfluß von Vorsätzen auf die Handlungsinitiierung. Ein Beitrag zur willenspsychologischen Frage der Realisierung von Absichten. Franfurt: Peter Lang.

antor N and Fleeson, W. (1994). Social intelligence and intelligent goal pursuit: A cognitive slice of motivation. In W. Spaulding (Ed.), Nebraska Symposium on Motivation (Vol. 41, pp. 125-180). Lincoln, N.E.; University of Nebraska Press.

Carver, C.S. and Scheier, M.F. (1981). Attention and self-regulation: A control-theory approach to human behaviors. New York: Springer.

Carver, C.S. and Scheier, M.F. (1989). Expectancies and coping: from test anxiety to pessimism. In R. Schwarzer, H.M. van der Ploeg and C.D. Spielberger (Eds.), Advances in test anxiety research (Vol. 6, pp. 3-11). Amsterdam: Swets \& Zeitlinger.

Deci, EL and Ryan R.M. (1991). A motivational approach to self: Integration in personality. In R. Dienstbier (Ed.), Nebraska Symposium an Motivation: Vol. 38. Perspectives on motivation (pp. 237-288). Lincoln, NE: University of Nebraska Press.

Dweck C S. (1991) Self-theories and goals: Their role in motivation, personality, and development. In R. Dienstbier (Ed.), Nebraska Symposium on Motivation: Vol. 38. Perspectives on motivation (pp. 199-255). Lincoln, NE: University of Nebraska Press.

Dweck, C.S. (1996). Implicit theories as organizers of goals and behavior. In P.M. Gollwitzer and J.A. Bargh (Eds.), The psychology of action: Linking cognition and motivation to behavior (pp. 69-90). New York: Guilford.

Emmons, R.A. (1986). Personal strivings: An approach to personality and subjective well-being. Journal of Personality and Social Psychology, 51, 1058-1068.

Emmons, R A (1992) Abstract versus concrete goais: Personal striving level, physical illness, and psychological well-being. Journal of Personality and Social Psychology, 62, 292-300.

Emmons, R.A. and King, L.A. (1988). Conflict among personal strivings: Immediate and long-term implications for

Fishbein, M. (1980). A theory of reasoned action: Some applications and implications. In H.E. Howe and M.M. Page (Eds.), Nebraska Symposium on Motivation (Vol. 27, pp. 65-116). Lincoln: University of Nebraska Press.

Frankl, V.E. (1959/1984). Man's search for meaning. New York, NY: Washington Square Press.

Frankl, V.E. (1959/1984). Man's search for meaning. New York, NY: Washington Square Press. motivation and cognition: Foundations of social behavior (Vol. 2, pp. 53-92). New York: Guilford.

Gollwitzer, P.M. (1991). Abwägen und Planen. Göttingen: Hogrefe.

Gollwitzer, P.M. (1993). Goal achievement: The role of intentions. In W. Stroebe and M. Hewstone (Eds.), European review of social psychology (Vol. 4, pp. 141-185), Chichester, UK: Wiley.

Gollwitzer, P.M. and Brandstätter, V. (1997). Implementation intentions and effective goal pursuit. Journal of Personality and Social Psychology, 73, 186-199.

Gollwitzer, P.M., Heckhausen, H. and Steller, B. (1990). Deliberative vs. implemental mind-sets: Cognitive tuning toward congruous thoughts and information. Journal of Personality and Social Psychology, 59, 1119-1127.

Gollwitzer, P.M. and Kinney, R.F. (1989). Effects of deliberative and implemental mind-sets on the illusion of control. Journal of Personality and Social Psychology, 56, 531-542.

Gollwitzer, P.M. and Moskowitz, G.B. (1996). Goal effects on action and cognition. In E.T. Higgins and A.W. Kruglanski (Eds.), Social psychology: A handbook of basic principles (pp. 361-399), New York: Guilford Press.

Gottschaldt, K. (1926). Über den Einfluß der Erfahrung auf die Wahrnehmung von Figuren: I. Über den Einfluß gehäufter Einprägung von Figuren auf ihre Sichtbarkeit in umfassenden Konfigurationen. Psychologische Forschung, 8, 261-317.

Heckhausen, H. (1991). Motivation and action. Heidelberg: Springer.

Higgins, E.T., Roney, C.J.R., Crowe, E. and Hymes, C. (1994), Ideal versus ought predilections for approach and avoidance: Distinct self-regulatory systems. Journal of Personality and Social Psychology, 66, $276-286$.

Hochbaum, G. (1958). Public participation in medical screening programs (DHEW Publication No. 572, Public Health Service). Washington, DC: U.S. Government Printing Office.

Horowitz, M.J. (1978). Image formation and cognition. New York: Appleton-Century-Crofts.

Johnston, M. (1996, May). Models of disability. The Psychologist, 205-210.

Johnston, W. A. and Dark, V.J. (1986). Selective attention. Annual Review of Psychology, 37, 43-75.

Kasser, T. and Ryan, R.M. (1993). A dark side of the American dream: Correlates of financial success as a central life aspiration. Journal of Personality and Social Psychology, 65, 410-422.

Kirk, C.C. (1994). Taming the diet dragon. St. Paul, Mn: Llewellyn.

Klinger, E. (1971). Structure and functions of fantasy. New York: Wiley.

Klinger, E. (1990). Daydreaming: Using waking fantasy and imagery for self-knowledge and creativity, Los Angeles: Tarcher. 
Külpe, O. (1904). Versuche über Abstraktion. In F. Schuhmann (Ed.), Bericht über den 1. Kongreß für experimentelle Psychologie (pp. 56-71). Leipzig: Barth.

Kuhl, J. (1984). Volitional aspects of achievement motivation and learned helplessness: Toward a comprehensive theory of action control. In B.A. Maher and W.B. Maher (Eds.), Progress in experimantal personality research (pp. 99-171). New York: Academic Press.

Kuhl, J. and Beckmann, J. (Eds.). (1985). Action control: From cognition to behavior. Berlin: Springer.

Kuhl, J. and Beckmann, J. (Eds.). (1994). Volition and personality: Action versus state orientation. Seattle: Hogrefe Huber.

Lengfelder, A. (1994). Die Bedeutung des Frontalhirns beim Abwägen und Planen. Frankfurt an Main: Peter Lang.

Leventhal, H. (1970). Findings and theory in the study of fear communications. In L. Berkowitz (Ed.), Advances in experimental social psychology (Vol. 5, pp. 119-186). New York: Academic Press.

Lewin, K. (1926). Vorsatz, Wille und Bedürfnis. Psychologische Forschung, 7, 330-385.

Lewin, K., Dembo, T., Festinger, L.A. and Sears, P.S. (1944). Level of aspiration. In J.M. Hunt (Ed.), Personality and the behavior disorders (Vol. 1, pp. 333-378). New York: Ronald.

Locke, E.A. and Latham, G.P. (1990). A theory of goal setting and task performance. Englewood Cliffs, NJ: Prentice Hall

Mahler, W. (1933). Ersatzhandiungen verschiedenen Realitätsgrades. Psychologische Forschung, 18, 27-89.

Malzacher, J.T. (1992). Erleichtern Vorsätze die Handlungsinitiierung? Zur Aktivierung der Vornahmehandlung. Unpublished doctoral dissertation, Ludwig-Maximilian-Universität, München.

Oettingen, G. (1996). Positive fantasy and motivation. In P.M. Goilwitzer and J.A. Bargh (Eds.), The psychology of action: Linking cognition and motivation to behavior (pp. 236-259). New York: Guilford.

Oettingen, G. (1997). Psychologie des Zukunftsdenkens. Göttingen: Hogrefe.

Oettingen, G. and Wadden, T.A. (1991). Expectation, fantasy, and weight loss: Is the impact of positive thinking always positive? Cognitive Therapy and Research, 15, 167-175.

Orbell, S. Hodgkins, S. and Sheeran, P. (1997). Implementation intentions and the theory of planned behavior. Personality and Social Psychology Bulletin, 23, 945-954.

Ovsiankina, M. (1928). Die Wiederaufnahme unterbrochener Handlungen. Psychologische Forschung, 11, 302-379.

Patterson, C.J. and Mischel, W. (1976). Effects of temptation-inhibiting and task-facilitating plans of self-control. Journal of Personality and Social Psychology, 33, 209-217.

Pösel, I. (1994). Wiederaufnahme unterbrochener Handlungen: Effekte der Bewußtseinslagen des Abwägens und Planens. Unpublished master's thesis, Universität Regensburg.

Rogers, R.W. (1983). Cognitive and psychological processes in fear appeals and attitude change: A revised theory of protection motivation. In J. Cacioppo and R. Petty (Eds.), Social psychophysiology: A sourcebook (pp. 153-176). New York: Guilford.

Rosenstock, I.M. (1966). Why people use health services. Milbank Memorial Fund Quarterly, 44, 94ff.

Rosenstock, I.M. (1974). The health belief model and preventive health behavior. Health Education Monographs, 2, 354-386.

Schaal, B. (1993). Impulskontrolle: Wie Vorsätze beherrschtes Handeln erleichtern. Unpublished master's thesis, Ludwig-Maximilian-Universität, München.

Scheier, M.F. and Carver, C.S. (1992). Effects of optimism on psychological and physical well-being: Theoretical overview and empirical update. Cognitive Therapy and Research, 16, 201-228.

Schwarzer, R. (1994). Optimism, vulnerability, and self-beliefs in health-related cognitions: A systematic overview. Psychology and Health, 9, 161-180.

Seehausen, R., Bayer, U. and Gollwitzer, P.M. (1994, September). Experimentelle Arbeiten zur vorsätzlichen Handlungsregulation. Paper presented at the biannual meeting of the German Psychological Association, Hamburg.

Seligman, M.E.P. (1991). Learned optimism. New York: Knopf.

Seligman, M.E.P., Peterson, C., Kaslow, N.J., Tanenbaum, R.L., Alloy, L.B. and Abramson, L.Y. (1984). Attributional style and depressive symptoms among children. Journal of Abnormal Psychology, 93, 235-238.

Shallice, T. (1982). Specific impaiments of planning. Philosophical Transactions of the Royal Society of London (Biological Sciences), B 298, 199-209.

Simonton, O.C., Matthews-Simonton, S. and Creighton; J. (1978). Getting well again. Los Angeles, CA: Tarcher.

Singer, J.L. (1966). Daydreaming. New York: Random House.

Steller, B. (1992). Vorsäize und die Wahmehmung günstiger Gelegenheiten. München: Tuduv.

Taylor, S.E. (1991). Health psychology (2nd ed.). New York: McGraw-Hill.

Taylor, S.E. and Brown, J.D. (1988). Illusion and well-being: A social psychological perspective on mental health. Psychological Bulletin, 103, 193-210.

Taylor, S.E. and Gollwitzer, P.M. (1995). Effects of mindset on positive illusions. Journal of Personality and Social Psychology, 69, 213-226. Watt, H.J. (1905). Experimentelle Beiträge zu einer Theorie des Denkens. Archiv für die gesamte Psychologie,
4, 289-436. 
Weinstein, N.D. (1980). Unrealistic optimism about future life events. Journal of Personality and Social Psychology, 39, 806-820.

Weinstein, N.D. (1982). Unrealistic optimism about susceptibility to health problems. Journal of Behavioral Medicine, 5, 441-460.

Wicklund, R.A. and Gollwitzer, P.M. (1982). Symbolic self-completion. Hillsdale, NJ: Erlbaum.

Witkin, H.A. (1950). Individual differences in ease of perception of embedded figures. Journal of Personality, $19,1-15$.

Wright, R.A. (1996). Brehm's theory of motivation as a model of effort and cardiovascular response. In P.M. Gollwitzer and J.A. Bargh (Eds.), The psychology of action: Linking cagnition and motivation to behavior. New York: Guilford.

Wright, R.A. and Brehm, J.W. (1989). Energization and goal attractiveness. In L.A. Pervin (Ed.), Goal concepts in personality and social psychology (pp. 169-210). Hillsdale, NJ: Erlbaum.

Tillman, D. and Cantor, J.R. (1976). Effect of timing of information about mitigating circumstances on emotional responses to provocation and retaliatory behavior. Journal of Experimental Social Psychology, 12, $38-55$. 